\title{
CRIME IS IN THE AIR: THE CONTEMPORANEOUS RELATIONSHIP BETWEEN AIR POLLUTION AND CRIME*
}

\author{
Malvina Bondy \\ London School of Economics \\ Sefi Roth \\ London School of Economics
}

Lutz Sager

Georgetown University

October 2019

\begin{abstract}
Many empirical studies have examined the various determinants of crime. However, the link between crime and air pollution has been largely overlooked. In this paper we study whether exposure to ambient air pollution affects crime using daily administrative data for London in 200405 . For identification, we estimate models with ward fixed effects and implement two instrumental variable strategies, using atmospheric inversions and wind direction as exogenous shocks to local pollution. We find that air pollution has a positive and statistically significant impact on overall crime and on several major crime categories, including those with economic motives. Importantly, the effect also occurs at pollution levels which are well below current regulatory standards and appears to be unevenly distributed across income groups. Our results suggest that reducing air pollution in urban areas may be an effective measure to reduce crime and that air pollution forecasts can be used to improve predictive policing.
\end{abstract}

Keywords: Air pollution; crime; economic incentives.

JEL codes: H23, K42, Q53.

${ }^{*}$ Corresponding author: Sefi Roth. The London School of Economics and Political Science, Houghton Street, London WC2A 2AE, UK. E-mail: s.j.roth@1se.ac.uk. We would like to thank Mirko Draca for sharing his data on crime in London and Gabriel Ahlfeldt, Felipe Carozzi, two anonymous referees, the editor, as well as, participants in the SERC-CEP Conference, LSE-NHH Workshop on Environmental and Development Economics, IZA Conference on Labor Market Effects of Environmental Policies, the Essen Health Conference and the University of Manchester - Applied Economics Seminar for helpful comments and suggestions. Sager gratefully acknowledges financial support by the Grantham Foundation for the Protection of the Environment and the UK's Economic and Social Research Council (ESRC). 


\section{Introduction}

Crime and its prevention is a major policy issue due to its significant social and economic costs. According to the U.K Government, the total cost of crime in England and Wales is approximately $£ 60$ billion per year ${ }^{1}$. This figure, which is far from comprehensive, suggests that effective crime reduction measures have the potential to provide substantial savings. Indeed, a large body of literature studying the determinants of crime has examined various measures used to tackle crime such as increased police presence and better education (Draca et al., 2011; Machin et al., 2011) ${ }^{2}$. However, the link between improved air quality and crime reduction has been largely overlooked in the empirical literature despite several potential pathways.

In this paper, we study whether short-term exposure to elevated levels of ambient air pollution affects crime in London. We believe that London provides an almost ideal setting for this type of study for two key reasons. First, the high quality of the daily administrative crime data - in conjunction with the extensive network of air pollution monitoring stations - allows us to overcome identification problems such as measurement error and the presence of unobserved correlated factors. Second, London is similar to many major cities around the world in terms of its characteristics. According to the 2017 Economist Safe Cities Index and recent figures from the World Bank, both pollution and safety levels in London are almost identical to other major cities such as Chicago and New York ${ }^{3}$. Therefore, our results could inform policymaking, not just in London, but also in other large cities around the world.

We estimate the effect of air pollution on crime using a unique data set, which combines readings of ambient air pollution concentrations with rich administrative records on over 1.8 million criminal offences recorded in London during the years 2004-2005. To account for potential confounders, we take the following measures. First, we rely on the panel structure of the data to estimate models with ward fixed effects. Second, we use two instrumental variable approaches, where we use atmospheric inversion and wind direction as exogenous shocks to local air pollution

\footnotetext{
${ }^{1}$ This figure is taken from the Home Office Research Study 217 (Brand and Price, 2000). In 2005, the Home Office revised the estimates for the total cost of crime against individual and households to about $£ 36.2$ billion per year but this figure does not include crimes against business and the public sector $($.

${ }^{2}$ Policymakers also tend to focus on these measures. For example, the mayor of London recently claimed that realterms cuts in various public services such as community education and the police had "reversed decades of progress in tackling the root causes of violent offending" (The Independent, 2018).

${ }^{3}$ The 2017 Economist Safe Cities Index, which ranks 60 major cities around the globe, placed London in the $20^{\text {th }}$ spot for overall safety (between Chicago (19) and New York (21)). The pollution data is for PM10.
} 
concentrations. Third, we use our instruments to confirm that the positive effect of pollution on crime also holds at different spatial scales. This enables us to account for the possibility that the location where the crime occurred may not always coincide with the location of the offender prior to the offence. Finally, we perform a range of robustness and placebo tests, which provide additional support to the causal interpretation of our analysis.

The results suggest that exposure to elevated levels of air pollution is associated with increased crime rates. In our fixed effects specification, we find that an additional 10 Air Quality Index (AQI) points increase the crime rate by $1.2 \%$ and experiencing an AQI of above 35 leads to $3.7 \%$ more crimes. The latter result, which is equivalent to 0.04 of a standard deviation, is economically significant and similar to the estimated effect of a $10 \%$ decrease in police activity (Draca et al., 2011) $)^{4}$. Our preferred instrumental variable approaches yield statistically similar results to our fixed effect model. More specifically, we find that an additional 10 AQI points increase the crime rate by $2.6 \%$ when instrumenting pollution with wind direction. Finally, we explore whether ambient air pollution has heterogeneous effects on crime types and across the income distribution. We find that air pollution affects several types of crime and that the effect appears to be unevenly distributed across resident income groups.

To discuss the possible underlying mechanism for our findings, we complement our empirical results with a formal economic framework rooted in the rational choice theory of crime (Becker, 1968). In the context of this seminal framework, the decision to commit a crime is a risky action and we expect short-term fluctuations in air pollution to influence criminal activity through any of the following three channels - (i) altering perceived payoffs, (ii) altering risk perceptions, or (iii) altering risk preferences. Based on our empirical results we posit that the effect of air pollution on crime is might be driven by higher discounting of future punishment (i.e. altering perceived payoffs). Given the strong underlying assumptions of this framework, we also discuss alternative possible explanations for the link between pollution and crime.

Overall, this study provides several important contributions to the literature on crime, as well as carrying important implications for public policy more broadly. First, our results suggest that improving air quality in urban areas may provide an effective way to reduce crime. Second, the link between pollution and crime suggests that we can potentially improve the deployment of

\footnotetext{
${ }^{4}$ Draca et al. (2011) focus on the effect of increased police presence following the July 2006 terror attacks in London.
} 
law enforcement resources (e.g. local police personnel) by incorporating information from pollution forecasts (predictive policing) $)^{5}$. Third, our results are present at levels which are well below current U.S Environmental Protection Agency (EPA) and U.K Department for Environment, Food \& Rural Affairs (DEFRA) standards which suggests that it may be economically beneficial to lower existing guidelines. Fourth, this study also contributes to the evolving body of research studying the link between ambient pollution and the impact on other aspects of human life such as productivity, cognitive performance and sports performance (GraffZivin and Neidell, 2012; Ebenstein et al., 2016; Lichter et al., 2017). More specifically, given the link between air pollution and crime, our results suggest that examining the effects of air pollution on health impacts alone may lead to a substantial underestimation of its societal costs.

Finally, while a few recent contributions have examined the link between air pollution and crime (see section II), there are several important differences between these papers and our study. Most notably, we provide evidence that pollution affects not only violent crime (which is the main focus of the other papers), but also other crimes including those that are economically motivated; that the positive effect of pollution on crime holds at different spatial scales by using two different instruments, and that the effect of air pollution on crime appears to be unevenly distributed across the income distribution. This paper also provides a systematic discussion regarding the potential underlying mechanism for the link between air pollution and crime, within an economic framework.

\section{Background: The Adverse Effects of Air Pollution on Human Life}

The adverse health effects of ambient air pollution are well-established in the epidemiology and economic literature. Early epidemiological studies documented a strong association between extreme pollution events, such as the London Great Smog, and mortality (Logan, 1953). Later studies, which evaluate the link between pollution and health with lower and more common air pollution levels, found that ambient pollution affects life expectancy and hospitalisation (Dockery et al., 1993; Pope et al. 1995). The economic literature, which better accounts for potential

\footnotetext{
${ }^{5}$ Predictive policing programs are already being used by many police forces around the world including several U.S states (e.g. California and Washington), European cities (mainly in the UK and the Netherlands) and in China (Suzhou). To the best of knowledge, these programs don't use data on air pollution in their analysis.
} 
confounders, has also documented a strong link between air pollution and various health outcomes such as infant mortality and emergency room visits (Chay and Greenstone, 2003; Schlenker and Walker, 2015). More recently, a new wave of studies has examined the impact of pollution on other aspects of human life. For example, Graff Zivin and Neidell (2012) presented robust evidence for a causal link between ozone and productivity of agricultural workers in California; Ebenstein et al. (2016) found that elevated levels of $\mathrm{PM}_{2.5}$ reduce student test scores among Israeli students; Sager (2016) documented a robust causal relationship between pollution and road safety in the U.K; and Lichter et al. (2017) showed that variation in pollution affects the performance of professional soccer players in Germany.

Despite this growing body of literature on the adverse effects of air pollution on many aspects of human life, the evidence on the link between pollution and crime is very scarce ${ }^{6}$. Reyes $(2007$; 2015) examines the link between childhood lead exposure and crime rates later in life in the United States. A recent paper in the psychology literature by Lu et al. (2018) finds an association between air pollution and a wide range of crimes in the United States by using yearly variations in crime and pollution and a robust set of controls. Finally, three recent papers in economics examine the contemporaneous link between air pollution and violent crime in the U.S using different identification strategies. Li (2017) uses non-attainment designation in the U.S. as a source of seasonal variation, Zou (2018) uses variation in pollution driven by daily monitoring intensity and Herrnstadt et al. (2018) use daily variation in wind direction. All three find positive effects of pollution on violent crime in the United States.

The above papers are the closest to our study but there are several important differences between these papers and our study. First, we analyse a wide range of crime types and find that pollution affects not only violent, interpersonal crime (which is the main focus of the other papers), but also other crimes including those that are more economically motivated. Second, since the location where the crime occurred may not always coincide with the location of the offender prior to the offence, our study confirms that the positive effect of pollution on crime holds at different

\footnotetext{
6 There are a few studies that examine the effect of other environmental factors, such as temperature, on crime. For example, a number of studies find a significant association between temperature and violent as well as property crimes (e.g. Ranson, 2014; Cohen and Gonzalez, 2018). A recent review of the literature on climate and conflict is provided by Burke et al. (2015).
} 
spatial scales, using two different instruments (atmospheric inversions and wind direction) ${ }^{7}$. Third, we also provide evidence regarding the distributional aspects, where we analyse the relationship between air pollution and crime across different resident income groups. Fourth, whilst the other papers remain fairly agnostic regarding the underlying mechanisms, we take our analysis one step further and investigate the influence of pollution on crime within a rational choice framework. By combining our theoretical framework with our empirical evidence, we are able to provide a systematic discussion on the potential underlying mechanisms for this link. Finally, our study is the only paper that investigates the potential link between air pollution and crime outside of the U.S.

\section{Data}

Our final data set combines several files that contain administrative information on crime rates, ambient air pollution, weather and various demographics. For crime information, we use data from the London Metropolitan Police Service which contains ward level detailed daily police reports of all recorded crimes in the Greater London area for the years 2004-2005 ${ }^{8}$. Importantly, the data allows us to know not just the number of crimes per ward per day, but also the type of crime. Furthermore, the file also provides data on police deployment, tube journeys and unemployment levels which were originally obtained and defined as follows. Data on police deployment was taken from the police service's human resource management system and contains the total weekly number of hours worked by officers for each of the 32 boroughs in London. The weekly data on the total number of tube journeys was taken from Transport for London (TFL) and information on borough's unemployment levels were taken from the U.K Quarterly Labour Force Survey (LFS) ${ }^{9}$.

For information on pollution, weather and atmospheric inversions, we use daily data from the Department for Environment Food and Rural Affairs (DEFRA, 2017), the Met Office (2012) and NASA (2013). The first two files provide information on daily means of five pollutants,

\footnotetext{
${ }^{7}$ Although many offences take place in close proximity to the offender's home address (Bernasco et al., 2013), it is very possible that offenders will also decide to attack in more distant locations. For example, Bernasco (2010) find that offenders are more likely to target not just their current but also at their former residential areas. If this is indeed the case, a highly localized empirical strategy may lead to spatial spillovers.

${ }^{8}$ This data file is taken from Draca et al. (2011). The file does not include data on the City of London, which is one of the 33 local authority districts of Greater London.

${ }^{9}$ In our analysis we divided the weekly total number of tube journeys in each borough by the number of tube stations in the same borough.
} 
temperature, relative humidity, rainfall and wind direction and speed from 96 monitoring stations in the London area (see figure 1). In our analysis we use the AQI, which is calculated according to the US EPA formula, as our main pollution measure. More specifically, we define the overall daily AQI as the highest AQI among the individual pollutants, which is in line with the EPA reporting guidelines. The last data file contains satellite-based readings of atmospheric temperature profiles from the NASA Atmospheric Infrared Sonder Level 3 data (AIRS Science Team/Joao Texeira, 2013), which provides atmospheric temperature profiles every 12 hours with a spatial resolution of $1^{\circ} \times 1^{\circ}(\mathrm{ca} .110 \mathrm{~km} \times 70 \mathrm{~km})^{10}$.

We assign pollution and weather to wards by linking it with the three monitoring stations closest to the ward centroid. We then use the mean value of those three measurements weighted by the inverse squared distance between station and ward. We also attempted alternative approaches of assignment and the results are nearly identical ${ }^{11}$. Finally, we add population data from London's Ward Atlas (2017) and data on house prices by ward from the Land Registry (2017) to test whether the effect of pollution on crime varies across the resident income groups.

Table 1 presents summary statistics for our key variables of interest. Our sample includes 455,520 observations of daily crime counts (over 1.8 million criminal offences in total) across 624 wards in London ${ }^{12}$. The average daily AQI and the number of crimes per 100,000 people during our sample period were 30.06 and 34.06 respectively. Figure 2 plots the distributions of AQI and the total number of crimes in our sample. In columns (2)-(3) of Table 1 we stratify the sample by the median house price. As expected, we don't find meaningful differences in temperature, relative humidity and rainfall. However, the table indicates that both, pollution levels and the average crime rate, are higher in wards where house prices are above the median.

\section{Empirical Strategy}

There are several identification challenges for inferring a causal link between pollution and crime. The prime concern is the possible presence of unobserved correlated factors. For example,

\footnotetext{
${ }^{10}$ Note that this is the spatial scale for atmospheric temperature profiles from satellite readings which we use only for the atmospheric inversion instrument. This is not the same as the temperature controls that we use throughout our analysis which are coming from the measuring stations (see Figure 1).

${ }^{11}$ Specifically, all key results are highly similar when using only the single closest monitor to each ward centroid or the unweighted average from the 3 closest monitors.

${ }^{12}$ The day of the July 2005 attack is dropped from the sample (reducing it to 730 days) leaving a sample of $730 * 624=455,520$ observations.
} 
if pollution is higher in poorer areas, a naïve simple linear regression estimate might overstate the effect of pollution on crime, as crime may be higher in those areas for other correlated reasons (e.g. lower quality of education). We overcome this and other related econometric challenges by using two separate identification strategies as follow.

\section{a. Panel Fixed Effects Model:}

In our first empirical approach, we crucially rely on the panel structure of the data to estimate models with ward fixed effects. More formally, we estimate models of the following form:

$$
\text { Crime }_{i t}=\exp \left\{\beta A Q I_{i t}+f\left(\text { Temp }_{i t}, R H_{i t}\right)+\tau \text { Wind }_{i t}+\omega \text { Rain }_{i t}+\boldsymbol{C}_{i t} \Pi+\boldsymbol{\mu}_{t}+\gamma_{i}\right\}+\varepsilon_{i t}
$$

Here, Crime $_{i t}$ is the number of crimes in ward $i$ on day $t$ and $A Q I_{i t}$ is the corresponding air quality index. We control for weather conditions through $f\left(T_{e m} p_{\mathrm{it}}, R H_{i t}\right)$, which is a flexible function of mean temperature and relative humidity ${ }^{13}$, as well as local measures of wind speed $\left(\operatorname{Wind}_{i t}\right)$ and total precipitation $\left(\operatorname{Rain}_{i t}\right) . \boldsymbol{C}_{i t}$ is a vector of local area controls accounting for time-varying conditions potentially related to pollution and $\mathrm{crime}^{14} . \boldsymbol{\mu}_{t}$ and $\gamma_{i}$ are time and ward fixed effects respectively. Finally, $\varepsilon_{i t}$ is an idiosyncratic error term. Throughout, we employ Poisson PseudoMaximum Likelihood (PPML) estimation with ward population as the offset unless noted otherwise $^{15}$.

Through the inclusion of ward fixed effects our identification relies on the comparison of crime levels between days with higher and days with lower pollution levels within the same ward. This approach removes any potential confounding from time-invariant structural differences between wards, which as mentioned above, is a prime concern.

\footnotetext{
${ }^{13}$ We control for a flexible influence of temperature and humidity by including: dummy variables for 5 temperature bins of equal size, $R H_{i t},\left(R H_{i t}\right)^{2}$, Temp $_{i t} \cdot R H_{i t}$, and $\left(T e m p_{i t} \cdot R H_{i t}\right)^{2}$.

${ }^{14}$ We rely here on the following control variables from the data compiled by Draca et al. (2011): borough-level unemployment rate, the number of tube journeys (separately measured for weekdays and the weekend), and the (natural logarithm of) total hours of police deployment per capita (these characteristics vary by week.). As the police deployment variable may in theory be an outcomes of the treatment ('bad control') we also analysed the data without including it as a control and the resulting estimates were almost unchanged. Finally, we find no evidence that pollution influences police deployment (see table A4) which suggests that police deployment is not an outcome of the treatment and is therefore not a 'bad control'.

${ }^{15}$ Compared to common log-linear OLS estimation, PPML makes use of zero counts and is consistent in the presence of heteroskedasticity (see e.g. Silva and Tenreyo, 2006). Compared to standard Poisson estimation, PPML does not constrain the conditional variance to be equal to the conditional mean.
} 
Weather controls are included because of well-documented evidence which shows that weather conditions can influence both pollution levels (Zannetti, 2013) and criminal activity (Burke et al., 2015; Cohen \& Gonzalez, 2018). We also include further control variables intended to account for time-varying local conditions that may influence criminal activity. Tube activity acts as a proxy for general levels of activity and crowdedness, which may again influence both pollution and crime. Unemployment rates and the level of police deployment serve as additional controls for potentially confounding factors. It is conceivable that more police officers being deployed influences both pollution and crime. Similarly, we may hypothesise that short-term fluctuations in unemployment are associated with both levels of pollution and crime ${ }^{16}$.

A final concern may be periodic co-movement between pollution and crime unrelated to the causal effect hypothesised above. For example, we may expect busy weekdays to differ from quiet Sundays both in pollution levels and criminal activity. To account for such systematic timevarying factors, we include in $\boldsymbol{\mu}_{t}$ a collection of time fixed effects. These include dummies for the Day of the Week to counter the potential short-run seasonality problem described above. We also introduce 24 year-month dummies intended to account for any larger seasonal co-movement as well as time trends. Finally, we include dummies accounting for the six-week period of intensified police presence following the July 2005 terror attack, both in London as a whole and in special focus areas, shown by Draca et al. (2011) as having influenced criminal activity.

\section{b. Instrumental Variable Models:}

We believe that our fixed effect strategy in conjunction with the range of control variables yields credible estimates of the effect of air pollution on crime. However, since air pollution levels are not randomly assigned, we cannot conclusively rule out the presence of unobserved timevarying correlated factors. Furthermore, the above model may be susceptible to reverse causality and measurement error which may also bias our results ${ }^{17}$. We therefore complement our above empirical strategy with instrumental variable approaches which rely on changes in wind direction

\footnotetext{
${ }^{16}$ As these variables may also be seen as outcomes of the treatment ('bad controls') we also analysed the data without including them as controls. The resulting estimates were very similar although slightly higher. We decided to take a conservative approach and keep them in our final specification, as this specification yield slightly lower estimates.

${ }^{17}$ A reverse causality is conceivable if more crime causes more pollution either by additional police cars on the streets or via changes to normal traffic flow.
} 
(and atmospheric temperature inversions) as exogenous shocks to local air pollution concentrations. More formally, we estimate the following model:

$$
\begin{gathered}
A Q I_{i t}=\boldsymbol{\rho}_{\boldsymbol{i}} \boldsymbol{W i n d D i r}_{i t}+\delta\left(\text { Temp }_{i t}, R H_{i t}\right)+\phi \text { Wind }_{i t}+\varphi \operatorname{Rain}_{i t}+\boldsymbol{C}_{i t} \boldsymbol{\kappa}+\boldsymbol{\eta}_{\boldsymbol{t}}+\theta_{i}+v_{i t} \\
\text { Crime }_{i t}=\exp \left\{\alpha A \widehat{Q I_{l t}}+f\left(\operatorname{Temp}_{i t}, R H_{i t}\right)+\tau \text { Wind }_{i t}+\omega \operatorname{Rain}_{i t}+\boldsymbol{C}_{i t} \Pi+\boldsymbol{\mu}_{\boldsymbol{t}}+\gamma_{i}\right\}+\varepsilon_{i t}
\end{gathered}
$$

Crime $_{i t}$ is again the offence count in ward $\mathrm{i}$ on day $\mathrm{t}$ and $A Q I_{i t}$ the corresponding pollution level. We rely on hourly observation on the principal direction of wind, which we aggregate into the share of hours in the 24-hour period in which wind blows from one of four directions, WindDir $_{i t}{ }^{18}$. Wind direction is known to influence concentrations of air pollutants and has been previously employed successfully as an instrument for air pollution (see for example Anderson, 2015).

Appendix Figure A1 illustrates the basic mechanism underlying our instrumental variable approach. It shows the mean AQI across all wards in London on days where the predominant wind direction is as indicated. It clearly shows that days on which the wind is blowing from the East and Southeast on average have a significantly higher AQI than days where the wind blows for example from the West. We exploit this relationship between wind and pollution.

We allow for the influence of wind direction on pollution ( $\rho_{i}$ in the first stage) to differ between five regions of London (Central, North, South, East, West) ${ }^{19}$. We do so because London covers a large area and wind patterns may transport pollution from different sources located in and around the city, which may result in the same wind direction having differential effects in different parts of the city. By allowing the first stage effect of wind direction on air pollution to differ between regions our approach is similar to that of Deryugina et al. (2016) who study the shortterm effect of fine particulate matter exposure on mortality and medical costs among the elderly

\footnotetext{
${ }^{18}$ More precisely, we use as instruments the share of hours in the 24 hours of each day in which the principal direction of wind has been identified to belong to the three quadrants $0-90^{\circ}, 91-180^{\circ}, 181-270^{\circ}$ respectively. The fourth quadrant serves as the baseline wind direction.

${ }^{19}$ The choice of regions is somewhat arbitrary, but results are robust to different groupings. In the results reported in this manuscript, we group boroughs into five regions as follows: West (Brent, Ealing, Harrow, Hillingdon, Hounslow, Richmond Upon Thames); North (Barnet, Enfield, Haringey, Waltham Forest); East (Barking and Dagenham, Bexley, Havering, Newham, Redbridge); Central (Camden, Hackney, Hammersmith and Fulham, Islington, Kensington and Chelsea, Tower Hamlets, Westminster); South (Lambeth, Southwark, Wandsworth, Bromley, Croyden, Greenwich, Kingston Upon Thames, Lewisham, Merton, Sutton).
} 
in the United States. We again include the same set of control variables and fixed effects used in our first empirical strategy described above. Our key identifying assumption is that - after controlling for weather conditions, fixed effects and other control variables - the average wind direction in ward $i$ on day $t$ is unrelated to criminal activity in ward $i$ on day $t$, except through its influence on air pollution.

We also use atmospheric temperature inversions as another instrument for pollution. While on most days temperature decreases with altitude, on some days the temperature is higher above than at ground-level. During such inversion episodes pollutants are trapped close to the ground, resulting in higher concentrations at ground-level. As inversion episodes have been used before as an instrument for plausibly exogenous variation in air pollution levels (for example in Arceo et al., 2016; Sager, 2016; Jans et al., 2018), we follow these examples. Specifically, we use as an instrument the continuous difference between temperatures at the ground-level and temperatures at ca. $750 \mathrm{~m}$ altitude (925hPa pressure level) and follow the same specifications as in equations (1) and (2) above.

These two instrumental variable strategies corroborate the findings of our fixed-effect strategy in two ways. First, these instruments - so long as they are valid - provide evidence of the robustness of our results to the presence of unobserved correlated factors. The fact that we obtain similar estimates with all three empirical strategies, including two separate instrumental variable approaches, strengthens our confidence in our results. Second, the two instruments induce plausibly exogenous variation in pollution levels at different spatial scales. Wind direction induces highly localized changes in air quality which enables us to detect an effect of pollution on crime at the level of London wards. However, criminal offenders move across space, which means that, the pollution level in the ward where the crime was committed may not fully account to the offender's pollution exposure in the time leading up to the crime. A highly localized empirical strategy may miss such spatial spillovers, while an analysis at a larger spatial scale would capture them. We therefore also use daily variation in temperature inversions as an instrument, and confirm the effect of pollution on crime at the borough and the Greater London levels.

Instrument validity requires that the chosen instrument-either wind direction or inversion episodes - do influence the concentration of pollution (Instrument Relevance), that there are no observations for which this relationship is systematically reversed (Monotonicity), and that the respective instrument only affects criminal activity through its influence on pollution (Exclusion 
Restriction). Both wind direction and inversions are clearly relevant instruments, as supported by the F-test statistics in Tables 4 and 5. Monotonicity may be violated if the same wind direction that blows pollution towards certain wards, blows it away from others. To account for this possibility, we allow wind direction to differentially affect pollution in different regions of London ${ }^{20}$. While this mitigates the threat, it is still possible that Monotonicity may be violated across wards within each region. Therefore, we also report results (in Table A3) using an alternative wind instrument based on the ranking of 4 and 8 wind directions according to their long-term average AQI in each ward. ${ }^{21}$ Monotonicity is less of a concern for the inversion instrument, which relies on variation at a larger geographic scale and the physical dynamics of atmospheric ventilation. It seems unlikely that there are regions (or time of year) for which inversion episodes systematically decrease instead of increase pollution levels. Finally, while the Exclusion Restriction cannot be tested for, we are not aware of any known effect of either wind direction or inversions on criminal activity. We perform several robustness checks and discuss below the possibility of unobserved time-varying correlated factors, which would endanger the Exclusion Restriction.

\section{Results}

\section{a. Main Results}

Table 2 reports on the link between air pollution and crime using our pooled PPML and fixed effects models. In the first two columns we present cross-sectional correlations between crime and ambient pollution. The coefficient estimate in column 1 suggests that an additional 10 AQI units are associated with an increase in crime by $10.5 \%$. In column 2 , we add our set of time varying controls for weather, police deployment and local economic conditions (e.g. unemployment rate). We find that an additional 10 units of AQI are associated with an increase of $3.6 \%$ in crime. Whilst both of these estimates are statistically significant at the $1 \%$ level, they are cross-sectional in nature which prevents a causal interpretation.

\footnotetext{
${ }^{20}$ First-stage results showing the influence of wind directions on AQI are shown in Appendix Table A2.

${ }^{21}$ Specifically, we create a separate ranking of wind directions for each ward according to their long-term AQI in that ward on days where that wind direction was most common. The instrument is then a discrete indicator for each day if the wind direction on that day was the ward's 1 st, $2 \mathrm{nd}, \ldots$ polluting wind direction.
} 
In columns 3-6, we exploit the panel structure of the data to estimate models with time and ward fixed effects. Column 3 , which estimates a within ward regression, suggests that 10 additional units of AQI lead to a $2.4 \%$ increase in crime. The estimate for our fixed effects specification, which includes the full set of controls and fixed effects (Year-Month, Day of the Week and ward), is reported in column 5. We find that additional 10 units of AQI increase crime by $1.2 \%$, an estimate significant at the 1 percent level. The coefficient corresponds to an elasticity of 0.04 which is similar to the effect of air pollution on the productivity of call centre workers in China (Neidell, 2017). Figure 3 complements our analysis in table 2 with a visual representation of the relationship between residual pollution and crimes. The figure clearly demonstrates that using variation within ward yield a strong positive link between pollution and crime. Finally, in column 6 of Table 2 we instead use crime rate per 100,000 people as our dependent variable in a linear second-stage specification (instead of PPML). We find that 10 additional units of AQI leads to 0.46 additional crimes per 100,000 people (or $1.4 \%$ of the mean).

In Table 3 we examine the possible non-linear relationship between pollution and crime by substituting our continuous AQI measure with dummy variables for different levels of pollution. The results reveal a monotonic positive relationship between pollution and crime. For example, column 4 which report estimates from our preferred fixed effects specification suggests that criminal activity in London increases by $3.7 \%$ on days with AQI above 35 . This estimate is statistically significant at the 1 percent level and equivalent to 0.04 of a standard deviation, which is very large and similar to the estimated effect of a $10 \%$ increase in police activity (Draca et al., 2011). Importantly, we find that these large effects are present at levels which are well below current regulatory standards as an AQI score between 0-50 is classified by the U.S EPA as "Good". Therefore, our results suggest that tightening existing pollution regulation may be economically beneficial.

Whilst we believe that our above empirical strategy yields credible evidence on the arguably causal link between air pollution and crime, we cannot conclusively rule out the presence of unobserved time-varying correlated factors ${ }^{22}$. Therefore, in Table 4 we report estimates from our main IV strategy, where we use wind direction as an instrument for pollution. In the first two columns we replicate our fixed effect strategy from Table 2 with the original and IV samples

\footnotetext{
${ }^{22}$ There are other potential empirical concerns in this context such as measurement error and reverse causality which our IV approach should overcome.
} 
(respectively) to verify that our results do not change due to the small reduction in the sample size. In columns 3-6 we report our IV PPML estimates using different sets of fixed effects and control variables. The first stage results clearly show that wind direction is indeed a strong predictor of local air pollution concentration and can therefore be used as an instrument ${ }^{23}$. Our second stage estimates are also highly economically and statistically significant across all specifications. In our preferred specification, which is reported in column 5, we find that 10 additional instrumented units of AQI increase crime by $2.6 \%$. This result corresponds to elasticity of 0.08 and is not statistically different from our fixed effect estimate. This estimate is large and suggests that the crime rate in London is about 25\% higher on the most polluted day ( $\mathrm{AQI}=103.6)$ compared to days with the lowest level of pollution (AQI=9.3).

In column 6 of Table 4 we use the crime rate per 100,000 people as our dependent variable. We find that 10 additional units of AQI lead to 0.945 additional crimes per 100,000 people $(2.8 \%$ of the mean). To further explore the welfare implication of this finding we use cost of crime estimates from Brand and Price (2000) and Dubourg and Hamed (2005) to perform a back of the envelope calculation. We find that one standard deviation increase in daily pollution levels leads to an additional $£ 782,512$ in crime costs for the 7.1 million residents of London in $2005 .^{24}$ To put this in perspective, Schlenker and Walker (2015) find that a one standard deviation increase in daily pollution levels for the 6 million residents living within $10 \mathrm{~km}$ of the airports in California leads to an additional $\$ 540,000(£ 279,000$ in $£ 2005)$ in hospitalization costs.

Our analysis so far has focused on daily variation in pollution levels (and crime) at the level of London wards. One potential concern in linking environmental conditions to criminal activity is the fact that criminals can be mobile across space. More specifically, the identification issue here is that the location of the crime may not always coincide with the location of the criminal throughout the hours and the day before the crime is committed. Our ward-level analysis would miss any effect of air quality in a specific ward on crimes committed in another ward. We thus replicate our analysis from Tables 2 and 4 at more aggregated spatial scales - boroughs and the whole of London. Such an approach will capture the relationship between pollution and all crimes in London, even those committed in a different ward. In Panels A and B of Table 5, we report

\footnotetext{
${ }^{23}$ Table A2 shows our first stage results.

${ }^{24}$ To do this, we only used cost estimates for crime categories that are effected by pollution according to our analysis in Section C below. We converted all unit costs to $£ 2005$ and calculated the mean cost per crime (£11,557).
} 
coefficient estimates for the impact of air pollution on crime at the borough and whole of London levels respectively. We use four different specifications in columns 1-4. The first is a full PPML specification with covariates (equivalent to Table 2, Column 5). The second uses the 24-hour share of four wind directions as an instrument for average daily pollution (equivalent to Table 4, Column 5). In the third column, we use atmospheric temperature inversions as an additional instrument for pollution and in the fourth, we use both instruments. As evident from the table, all four models suggest a positive effect of pollution on crime. While the sample size is significantly smaller than in Tables 2 and 4, we still have a strong first stage, the coefficient estimates are significantly different from zero, and the instrumental variable estimates are not statistically different from each other ${ }^{25}$. Overall, our analysis confirms that the positive effect of pollution on crime holds at three different spatial scales - at the ward-level, the borough level and the level of aggregate Londonand using three different instrumental variable approaches.

\section{b. Robustness Checks}

We conduct several placebo exercises and robustness tests to further support the causal interpretation of our analysis. First, we perform a placebo exercise in which we test the link between crime and air pollution concentration on irrelevant days ${ }^{26}$. Table A1 presents our set of results, where we look at pollution levels in the previous and later weeks, months and years ${ }^{27}$. Columns 3 and 4 replicate results from our preferred instrumental variable specification (Table 4 , Column 5), which produce statistically significant estimates only for same-day pollution. The results confirm that the link between pollution and crime is present only on the same day with no significant relationships between the placebo pollution readings and crime.

Second, we examine whether our results are sensitive to 6 alternative empirical specifications with AQI instrumented wind direction. Column (1) and (2) of Table A3, report on estimates from models with a log-linear specification and alternative weather controls (10 bins of equal size for each temperature, humidity, wind speed, and rainfall) respectively. The estimates remain statistically significant and similar to the estimated effect of our main IV specifications. In

\footnotetext{
${ }^{25}$ Given the large spatial nature of atmospheric inversions, there is very limited variation between boroughs and it is better to use this type of instrument at the London level. Furthermore, for the specification with both wind and inversion instruments (London level) the Sargan-Hansen test for over identifying restrictions is 1.50 with a corresponding p-value of 0.68 .

${ }^{26}$ Similar approach to Ebenstein et al. (2016).

${ }^{27}$ More specifically, we replace our independent variable with 7,31 and 365 days lagged and leads pollution level.
} 
Column (3) we replace our day-of-week and year-month fixed effects with date fixed effects to ease concern regarding that some particular days of the year might have high pollution and high crime levels across the whole city due to other factors (e.g. sporting events and festivals). Importantly, we believe that this is unlikely to affect the validity of our IV estimates as these types of factors are unlikely to be correlated with wind direction and inversions. Nevertheless, it remains a possible concern to our fixed effect model without instruments. As evident from the table, the estimate remains positive and statistically significant. Next, we address concerns regarding the monotonicity assumption of our wind direction instrument (as discussed in the empirical strategy section). More specifically, in columns (4) and (5) we use an alternative wind instrument based on the long-term ranking of 4 (or 8) wind directions according to their long-term average AQI in each ward. Reassuringly, the results are similar to our preferred estimate reported in Table 4. Finally, in column 6 we include additional controls for AQI levels from the previous and following days. Again, the estimate remains almost identical but less precisely estimated. Overall, all of the alternative specifications yield similar estimates and we therefore conclude that our results are not sensitive to alternative models.

\section{c. Heterogonous Effect of Air Pollution}

In this section, we examine the heterogonous effect of air pollution across the income distribution and on different types of crime. The motivation for the former is to explore the popular notion that environmental externalities disproportionally affect certain groups of individuals across the income distribution (Hsiang et al., 2017). The motivation for the latter is twofold. First, to study whether some crimes are more sensitive to air pollution. Second, to use the results, in conjunction with our formal economic framework, to discuss the underlying mechanism for our headline findings. In Figure 5, we investigate whether our estimates vary across resident income groups. This analysis is challenging as we need to distinguish between two possible cases. First, different resident groups in the population may be exposed to different levels of pollution. Therefore, if the relationship between crime and pollution is nonlinear, those groups with higher exposure will be more affected by an additional unit of pollution. Second, the marginal unit of pollution may affect some groups more than others for other reasons (e.g. vulnerability $)^{28}$.

\footnotetext{
${ }^{28}$ For a full discussion on this subject see Hsiang et al. (2017).
} 
To examine these aspects, we stratify our sample of 624 wards according to their average house price as a proxy for income (Figure 4). In Figure 5, we plot the point estimates and corresponding $95 \%$ confidence interval for each quantile ${ }^{29}$. We also include the long-term average AQI levels for each decile and find that long term pollution concentrations tend to be larger in wards with higher average house prices. Overall, we find that the larger effects seem to occur mainly at the bottom of the income distribution. This suggests that despite relatively low exposure, the effect of pollution on crime is large in the less wealthy wards.

Next, we examine the effect of different types of crime in Figure 6. The results suggest that 2 out of the 5 major crime types are positively affected by pollution. In Figure 7 we break up those 5 major crimes into sub-categories, which suggests two interesting findings. First, air pollution affects crimes that are more likely to be spontaneous (interpersonal violence, criminal damage), but not premeditated crimes (crimes which involve planning such as burglaries and robberies). Second, the effect exists not just in violent crimes but also in other types of crimes including those that are economically motivated. Previous research in economics focus only on violent crimes, but our results are consistent with results in $\mathrm{Lu}$ et al. (2018). We discuss the potential mechanisms for our findings in the next section.

\section{Discussion of possible underlying mechanisms}

Acute exposure to air pollution leads to a myriad of physiological effects documented in the medical literature. It can impair the transport of oxygen to the brain, which in turn may reduce cognitive performance (Kampa and Castanas, 2008). In addition, pollution exposure has been linked to elevated levels of stress hormones such as cortisol (Li et al., 2017) and serotonin levels (Murphy et al., 2013). Both of these are linked to the behavioural changes that may plausibly result in more criminal activity.

To better understand the potential mechanism for the link between pollution and crime we adopt an economic perspective. We embed our analysis in the canonical rational choice model of crime proposed by Becker (1968) and Ehrlich (1973), which characterises the supply of criminal activity as driven by individual decision making under risk. Whilst the rational choice is only one of many frameworks to understand criminal behaviour, we think that this leading economic

\footnotetext{
${ }^{29}$ Estimates in Figure 5 are from separate regressions for each quantile. However, estimates for a joint regression including quantile interactions look very similar.
} 
paradigm for crime analysis, provides valuable structure when investigating the effect of air pollution on crime - especially in our study which examines a wide range of crime types and their short-term fluctuations. Therefore, this section will leverage the rational choice framework to uncover the underlying mechanism for our empirical findings but will also discuss alternative frameworks.

Following Becker (1968), a potential offender $j$ chooses to commit an offence if her expected utility from the crime outweighs the utility of a certain outside option, so if:

$$
p_{j} U_{j}\left(W_{j}^{c}-\beta S_{j}^{c}\right)+\left(1-p_{j}\right) U_{j}\left(W_{j}^{c}\right)>U_{j}\left(W_{j}^{n c}\right)
$$

Given a fixed outside option $W_{j}^{n c}{ }^{30}$, any potential offender $j$ is more likely to commit an offence if: (i) the payoff from crime $W_{j}^{c}$ increases relative to the cost of future punishment $S_{j}^{c}$ which is discounted at the rate $\beta$, (ii) the probability of being punished $p_{j}$ is lowered, or (iii) the potential offender's preferences $U_{j}($.$) become more risk accepting { }^{31}{ }^{32}$.

As outlined above, exposure to air pollution has been linked to changes in behaviour, productivity and well-being. In the context of the rational choice framework, we may expect shortterm fluctuations in air pollution to influence criminal activity through any of the following three channels - (i) altering perceived payoffs $\left(W_{j}^{c}\right.$ and $\left.\beta S_{j}^{c}\right)$, (ii) altering risk perceptions $\left(p_{j}\right)$, or (iii) altering risk preferences $\left(U_{j}().\right)$. In principle, the potential influence of air pollution may then either increase or decrease criminal activity. For example, if elevated levels of air pollution lead to increased risk aversion, we would expect to see a decrease in criminal activity on high polluted days. Conversely, if air pollution reduces the expected cost of future punishment, via lower discounting $(\beta)$ for example, we would expect to observe an increase in crime on days with pollution. We will now explore these channels in more detail.

\section{Risk perception and risk preferences:}

\footnotetext{
${ }^{30}$ A large share of the economics of crime literature focuses on longer term determinants of crime, so that $W_{j}^{n c}$ might for example correspond to earnings from legitimate work. In our framework, which focuses on short-term decisions, $W_{j}^{n c}$ may reflect factors shaping the utility of refraining from committing an offence on that given day.

${ }^{31}$ There is indeed robust evidence that the expected gain as well as the likelihood and magnitude of punishment do influence the supply of offences in the expected direction. Most recently, Draca et al. (2018) find substantial responses of property crimes to commodity prices in the United Kingdom for the years 2002-2012.

${ }^{32}$ Alternatively, we can use a more common additive time separable formulation as follow: $\mathrm{U}_{\mathrm{j}}\left(\mathrm{W}_{\mathrm{j}}^{0, \mathrm{c}}\right)+\beta\left[\mathrm{p}_{\mathrm{j}} \mathrm{U}_{\mathrm{j}}\left(\mathrm{W}_{\mathrm{j}}^{1}-\mathrm{S}_{\mathrm{j}}^{\mathrm{c}}\right)+\left(1-\mathrm{p}_{\mathrm{j}}\right) \mathrm{U}_{\mathrm{j}}\left(\mathrm{W}_{\mathrm{j}}^{1}\right)\right]>\mathrm{U}_{\mathrm{j}}\left(\mathrm{W}_{\mathrm{j}}^{0, n c}\right)+\beta \mathrm{U}_{\mathrm{j}}\left(\mathrm{W}_{\mathrm{j}}^{1}\right)$
} 
Changes that lead to more risk taking should be expected to also lead to more criminal offences. In the expected utility framework presented above, more risk taking and hence more crime, can result from changes in either risk preferences or risk perceptions. Existing evidence does not support changes in risk perception or risk preferences as an explanation for the observed effect of air pollution on crime. To explain an increase in crime, elevated levels of air pollution should be linked to a more optimistic evaluation of one's odds of getting away with a crime unpunished (lower $\mathrm{p}_{\mathrm{j}}$ ) or a change towards more risk loving preferences (higher $\mathrm{U}_{\mathrm{j}}{ }_{\mathrm{j}}($.$) ). One$ possible way in which pollution may affect the actual likelihood of getting away with a crime is via changes in police activity. We test directly for the potential effect of pollution on police deployment in Appendix Table A4. Here, we again use our full specification-a PPML model with AQI instrumented by wind direction-but replace the outcome variable in the second-stage with the number of police units employed. As police deployment data is weekly, but pollution is measured at a daily level, we include both results for an analysis at the daily (Column 1) and the weekly level (Column 2). We do not find evidence that air pollution levels influence police deployment.

While the existing empirical evidence on air pollution and risk taking is limited, it suggests an association in the opposite direction. Heyes et al. (2016) provide suggestive evidence that risk taking in financial markets is lower on days with elevated levels of air pollution. However, one may doubt the relevance of the behaviour of investment professionals for the understanding of criminal activity. We thus perform an additional test to check for an association between risk taking and air pollution using data on UK National Lottery sales. More specifically, we use data on over 1,044 weeks of lottery draws (Wednesday and Saturday draw each) between 1998 and $2018^{33}$. Again, we control for the same set of nation-wide weather conditions (temperature, relative humidity, their interactions and squares, wind speed, and precipitation) as well as fixed effects. We carry out this analysis once using observed AQI (Table A4, Column 3) and once instrumenting AQI using average wind direction (Column 4). We do not find evidence that pollution has an effect on lottery sales.

This argument is also in line with the medical literature. Experimental evidence documents that, if anything, subjects become more risk averse when administered the stress hormone cortisol

\footnotetext{
${ }^{33}$ We use data on Main Sales (Saturday and Wednesday) in the UK National Lottery available from http://lottery.merseyworld.com. Data cover all weeks in 1998-2018.
} 
(Kandasamy et al., 2014) or when exposed to physical stress (Porcelli and Delgado, 2009). As we discuss further below, acute exposure to air pollution has been linked to elevated levels of cortisol (Li et al., 2017). We would consequently expect to result in individuals becoming more risk averse when exposed to higher levels of pollution. In sum, both existing empirical evidence and our rudimentary analysis using lottery sales suggest that more risky behaviour is unlikely to explain the observed increase in criminal activity on polluted days.

\section{Perceived payoff vs. punishment: The potential role of discounting}

If we wish to maintain the rational choice framework outlined above, and by the principle of exclusion, our results suggest that the increase in criminal activity may be driven by changes in the perceived gain relative to the punishment. Such a change in the perceived costs and benefits of a criminal offence can be driven by two changes - an increase in the perceived benefit $\left(W_{j}^{c}\right)$, or a decrease in the perceived cost $\left(S_{j}^{c}\right)$ discounted at the rate $\beta$,

A first channel through which pollution may affect crime is by increasing the perceived benefit $\left(W_{j}^{c}\right)$. While it is plausible that heightened aggression (or similar effects on emotional disposition) might drive an increase in the perceived benefit of interpersonal crime, it seems unlikely that altered emotional disposition affects the perceived benefit of crimes that are economically motivated and often committed by "professional" criminals. For example, we would not expect the emotional disposition of a pickpocket to significantly alter her expected gain from theft. We find that pollution drives several types of crimes (Figures 6-7), not only those which are interpersonal but also those which are more economically motivated ${ }^{34}$. Therefore, we conclude that an increase in the perceived benefit $\left(W_{j}^{c}\right)$ of crime is not consistent with our findings.

Whilst we do not expect air pollution today to influence sentencing $\left(S_{j}^{c}\right)$ which occurs in the future (discussed further below), there is evidence from the medical literature which suggests that air pollution exposure may alter the relative perceived costs of punishment by raising the effective discount rate $(\beta)$ applied to the future prospect of punishment. Acute exposure to elevated levels of air pollution has been linked to a heightened concentration of stress hormones. In a rare

\footnotetext{
34 This is in line with a recent paper in the psychology literature, which finds an association between air pollution and a wide range of crimes in the United States (Lu et al., 2018). Similarly, Sager (2016) finds an effect of pollution on traffic accidents, but not on the share involving "hit-and-run", which may be considered particularly unethical and aggressive behavior.
} 
experimental study, Li et al. (2017) provide evidence that acute exposure to elevated levels of PM2. $5^{35}$ leads to significant increases in cortisol (hydrocortisone), cortisone, epinephrine, and norepinephrine. Changes in blood levels of stress hormones are in turn expected to result in behavioural change. More specifically, heightened concentrations of stress hormones, especially cortisol, have been shown to alter time-preferences. In a controlled experiment, Riis-Vestergaard et al. (2018) find that subjects that were administered cortisol 15 minutes before the experimental task exhibited a strongly increased preference for small immediate rewards relative to larger but delayed rewards. The same was found in studies that randomly assigned physical stress rather than administering stress hormones. Again, individuals subject to physical stress (or pain) exhibited greater impatience than relevant control groups (Delaney et al., 2014; Koppel et al., 2017). In sum, acute exposure to elevated levels of air pollution (PM2.5) may temporarily increase the discount rate applied to intertemporal trade-offs via its effect on blood levels of stress hormones. Increased discounting lowers the cost associated with potential future punishment $\left(S_{j}^{c}\right)$ and consequently results in an increase in criminal offences. Increased discounting also has the potential to reconcile the increase in crime (where potential future punishment is discounted relative to immediate gains) with the observed decrease in lottery sales (where potential future winnings are discounted relative to immediate ticket costs).

While we work within the rational choice framework, there are evidently other models that can explain the relationship between air pollution and crime. We do not have clear evidence to support these alternative models but we cannot conclusively reject them either. One example is based on various findings in the psychology literature that may suggest a link between air pollution and aggressive behaviour - either through physical discomfort, lowered serotonin levels, or neuroinflammation (e.g. Rammal, 2010; Crockett et al., 2013). In fact, this is the motivating hypothesis for many of the working papers which we mentioned in section 2 , that investigate the relationship between air pollution and violent crime. While they focus only on violent crimes, we investigate various types of crime, including those which are not commonly linked to aggressive behaviour (e.g. pickpocketing) and therefore we believe that this channel is less consistent with our results.

\footnotetext{
${ }^{35} \mathrm{Li}$ et al. (2017) conduct a randomised, double-blind crossover trial where subjects (college students) have air purifiers installed in their dormitories for a period of 9 days. Some purifiers are functioning (mean PM2.5 exposure of $24 \mathrm{mg} / \mathrm{m} 3$ ), others are not (mean PM2.5 exposure of $53 \mathrm{mg} / \mathrm{m} 3$ ).
} 
Of course, another typology of crimes may lead to different conclusions regarding the likely mechanism. Other prominent theories of crimes which focus on persistent personality traits (e.g. Nagin \& Paternoster, 1993) or social structure (Saw \& McKay, 1942; Bursik, 1988) are also less applicable in the context of our study which focuses on short-term (daily) fluctuations in crime. Finally, as air pollution negatively affects cognition and cognitive performance (e.g. Ebenstein et al. 2016), we cannot rule out the possibility that individual miscalculate the costs and benefits associated with crime. However, for this channel to be the driver of our results, air pollution should be systematically correlated with over- (under-) estimation of future benefits (costs). It is not clear why we should expect that.

\section{Conclusion}

This paper investigates the potential link between ambient air pollution and crime. Using two separate identification strategies, we find that daily variation in air pollution is positively linked to higher crime rates in London. We also find that pollution affects several crime types but appears to have larger effects on crimes which are more spontaneous. Based on the rational choice model and our empirical results, we posit that a possible underlying channel for our findings is higher discounting of future punishment on high pollution days. Finally, we investigate whether our estimates vary across resident income groups and find that the larger effects seem to occur mainly in less wealthy wards.

While the results are robust to a wide range of different specifications it is important to note two potential caveats. First, since our data provides information on reported crimes, it is theoretically possible that reporting itself is affected by pollution. We believe that this is unlikely to drive our results since we find that pollution affects types of crimes that are likely to be reported (due to their severity or for insurance purposes). Second, while we provide a systematic discussion

on the potential pathways of our findings, our results are reduced form and cannot causally identify the exact mechanisms. Overall, the study provides robust evidence that environmental factors are an important determinant of crime. Whilst previous studies focused on weather conditions, which are unlikely to be shaped by policymakers, we have studied an environmental condition which can be regulated. Our results suggest that improving air quality in urban areas by tighter environmental policy may provide an effective way to reduce crime. Furthermore, our results are present at levels which are well below current U.S Environmental Protection Agency (EPA) and U.K Department 
for Environment, Food \& Rural Affairs (DEFRA) standards which further suggest that it may be economically beneficial to lower existing guidelines. Finally, given the link between air pollution and crime, our results therefore suggest that examining the effects of air pollution on health impacts alone may lead to a substantial underestimation of its societal costs. 


\section{References}

Anderson, Michael L (2015). As The Wind Blows: The Effects of Long-Term Exposure to Air Pollution on Mortality. NBER Working Paper No. 21578. National Bureau of Economic Research.

Becker, Gary S. (1968). Crime and punishment: An economic approach. In The economic dimensions of crime, 13-68. Palgrave Macmillan, London.

Bernasco, Wim. (2010). A sentimental journey to crime: Effects of residential history on crime location choice. Criminology, 48(2), 389-416.

Bernasco, Wim, Richard Block, and Stijn Ruiter (2013). Go where the money is: Modelling street robbers' location choices. Journal of Economic Geography, 13(1), 119-143.

Brand, Sam., and Price, Richard (2000). The economic and social costs of crime, Home Office Research Study 217.

Burke, Marshall, Solomon M. Hsiang, and Edward Miguel (2015). Climate and Conflict. Annual Review of Economics, 7, 577-617.

Chay, Kenneth Y., and Michael Greenstone (2003). The impact of air pollution on infant mortality: evidence from geographic variation in pollution shocks induced by a recession. Quarterly Journal of Economics, 118(3), 1121-1167.

Cohen, Francois, and Fidel Gonzalez (2018). Understanding interpersonal violence: the impact of temperatures in Mexico. GRI Working Paper No. 291, Grantham Research Institute on Climate Change and the Environment.

Crockett, Molly J., Annemieke Apergis-Schoute, Benedikt Herrmann, Matthew D. Lieberman, Ulrich Müller, Trevor W. Robbins, and Luke Clark (2013). Serotonin modulates striatal responses to fairness and retaliation in humans. Journal of Neuroscience, 33, 3505-3513.

Delaney, Liam, Günther Fink, and Colm P. Harmon (2014). Effects of Stress on Economic Decision-Making: Evidence from Laboratory Experiments. Discussion Paper No. 8060, IZA.

Deryugina, Tatyana, Garth Heutel, Nolan H. Miller, David Molitor, and Julian Reif (2016). The mortality and medical costs of air pollution: Evidence from changes in wind direction. NBER Working Paper No. 22796, National Bureau of Economic Research.

Department for Environment, Food and Rural Affairs (2017). Automatic Urban and Rural Network. Data retrieved 26th November 2017 at https://uk-air.defra.gov.uk/data/data_selector.

Dockery, Douglas W., C. Arden Pope, Xiping Xu, John D. Spengler, James H. Ware, Martha E. Fay, Benjamin G. Ferris Jr, and Frank E. Speizer (1993). An association between air pollution and mortality in six US cities. New England Journal of Medicine, 329(24), 1753-1759. 
Draca, Mirko, Stephen Machin, and Robert Witt (2011). Panic on the streets of London: Police, crime, and the July 2005 terror attacks. American Economic Review, 101(5), 2157-81.

Dubourg, Richard., Hamed, Joe. and Thorns, Jamie (2005). The economic and social costs of crime against individuals and households 2003 / 04, Home Office Online Report No. 30/05.

Ebenstein, Avraham., Lavy, Victor., \& Roth, Sefi. (2016). The long-run economic consequences of high-stakes examinations: Evidence from transitory variation in pollution. American Economic Journal: Applied Economics, 8(4), 36-65.

Ehrlich, Isaac. (1973). Participation in Illegitimate Activities: A Theoretical and Empirical Investigation. Journal of Political Economy, 81(3), 521-565.

Graff Zivin, Joshua, and Matthew Neidell (2012). The impact of pollution on worker productivity. American Economic Review, 102(7), 3652-73.

Heyes, Anthony, Matthew Neidell, and Soodeh Saberian (2016). The Effect of Air Pollution on Investor Behavior: Evidence from the S\&P 500. NBER Working Paper No. 22753, National Bureau of Economic Research.

Herrnstadt, Evan, Anthony Heyes, Erich Muehlegger, and Soodeh Saberian (2018). Air Pollution as a Cause of Violent Crime. Mimeo.

Hsiang, Solomon, Paulina Oliva, and Reed Walker (2019) "The distribution of environmental damages." Review of Environmental Economics and Policy 13, no. 1: 83-103.

Jans, Jenny, Per Johansson, and J. Peter Nilsson (2018). Economic status, air quality, and child health: Evidence from inversion episodes. Journal of health economics, 61, 220-232.

Kampa, Marilena, and Elias Castanas (2008). Human health effect of air pollution. Environmental Pollution, 151, 362-367.

Koppel, Lina, David Andersson, Kinga Posadzy, Daniel Västfjäll, and Gustav Tinghög (2017). The effect of acute pain on risky and intertemporal choice. Experimental Economics, 20, 878-893.

Land Registry, HM (2017). Average house prices by borough, ward, MSOA, LSOA \& postcode. Data retrieved 13th December 2017 at https://data.london.gov.uk/dataset/average-house-prices.

Li, Huichu, Jing Cai, Renjie Chen, Zhuohui Zhao, Zhekang Ying, Lin Wang, Jianmin Chen et al. (2017). Particulate matter exposure and stress hormone levels: a randomized, double-blind, crossover trial of air purification. Circulation, 136(7), 618-627.

Li, Teng (2018). The Effect of Air Pollution on Criminal Activities: Evidence from the NOx Budget Trading Program. Mimeo 
Lichter, Andreas, Nico Pestel, and Eric Sommer (2017). Productivity effects of air pollution: Evidence from professional soccer. Labour Economics, 48, 54-66.

Logan, W. P. D. (1953). Mortality in the London fog incident, 1952. The Lancet, 261(6755), 336338.

Lu, Jackson G., Julia J. Lee, Francesca Gino, and Adam D. Galinsk. (2018). Polluted morality: Air pollution predicts criminal activity and unethical behavior. Psychological Science, 29(3), 340-355.

Machin, Stephen, Olivier Marie, and Sunčica Vujić (2011). The crime reducing effect of education. Economic Journal, 121(552), 463-484.

Met Office (2012). Met Office Integrated Data Archive System (MIDAS) Land and Marine Surface Stations Data (1853-current). NCAS British Atmospheric Data Centre. Data retrieved 23rd Nov. 2017, http://catalogue.ceda.ac.uk/uuid/220a65615218d5c9cc9e4785a3234bd0.

Murphy, Shannon R., Edward S. Schelegle, Lisa A. Miller, Dallas M. Hyde, and Laura S. Van Winkle (2013). Ozone exposure alters serotonin and serotonin receptor expression in the developing lung. Toxicological Sciences, 134, 168-179.

Neidell, Matthew (2017). Air pollution and worker productivity. IZA World of Labor.

Pope 3rd, C. A., David V. Bates, and Mark E. Raizenne (1995). Health effects of particulate air pollution: time for reassessment?. Environmental Health Perspectives, 103(5), 472.

Rammal, Hassan, Jaouad Bouayed, and Rachid Soulimani (2010). A direct relationship between aggressive behaviour in the resident/intruder test and cell oxidative status in adult male mice. European Journal of Pharmacology, 627, 173-176.

Ranson, Matthew. (2014). Crime, weather, and climate change. Journal of Environmental Economics and Management, 67(3), 274-302.

Reyes, Jessica Wolpaw (2007). Environmental policy as social policy? The impact of childhood lead exposure on crime. The BE Journal of Economic Analysis \& Policy, 7(1).

Reyes, Jessica Wolpaw (2015). Lead exposure and behavior: Effects on antisocial and risky behavior among children and adolescents. Economic Inquiry, 53(3), 1580-1605.

Riis-Vestergaard, Michala Iben, Vanessa van Ast, Sandra Cornelisse, Marian Joëls, and Johannes Haushofer (2018). The effect of hydrocortisone administration on intertemporal choice. Psychoneuroendocrinology, 88, 173-182.

Sager, Lutz (2016). Estimating the effect of air pollution on road safety using atmospheric temperature inversions. GRI Working Paper No. 251, Grantham Research Institute on Climate Change and the Environment. 
Schlenker, Wolfram, and W. Reed Walker (2015). Airports, air pollution, and contemporaneous health. Review of Economic Studies, 83(2), 768-809.

Silva, JMC Santos, and Silvana Tenreyro (2006). The log of gravity. Review of Economics and Statistics, 88(4), 641-658.

Ward Atlas (2017). Ward Profiles and Atlas. Data retrieved 7th December 2017 at https://data.london.gov.uk/dataset/ward-profiles-and-atlas.

Zou, Eric (2018). Unwatched Pollution: The Effect of Intermittent Monitoring on Air Quality. Mimeo

http://www.independent.co.uk/news/uk/politics/sadiq-khan-crime-weak-causes-violence-londonmet-police-theresa-may-home-office-stabbings-murders-a8141436.html 
Table 1

Descriptive Statistics

\begin{tabular}{|c|c|c|c|}
\hline \multirow[b]{2}{*}{ Variable } & \multirow[b]{2}{*}{$\begin{array}{l}\text { All } \\
(1) \\
\end{array}$} & \multicolumn{2}{|c|}{ By House Prices } \\
\hline & & $\begin{array}{c}\text { Low } \\
(2)\end{array}$ & $\begin{array}{c}\text { High } \\
\text { (3) }\end{array}$ \\
\hline \multirow[t]{2}{*}{ Crime (log) } & 1.39 & 1.43 & 1.36 \\
\hline & $(0.67)$ & $(0.64)$ & $(0.70)$ \\
\hline \multirow[t]{2}{*}{ Crime (\# per 100k population) } & 34.06 & 32.73 & 35.38 \\
\hline & (38.43) & (24.93) & $(48.25)$ \\
\hline \multirow[t]{2}{*}{ Population of ward } & 11,900 & 12,152 & 11,648 \\
\hline & $(1,915)$ & $(1,788)$ & $(2,003)$ \\
\hline \multirow[t]{2}{*}{ Air Quality Index (AQI) } & 30.06 & 28.51 & 31.60 \\
\hline & (9.177) & $(8.060)$ & (9.934) \\
\hline \multirow{2}{*}{$\operatorname{PM} 10\left(\mu \mathrm{g} / \mathrm{m}^{3}\right)$} & 28.05 & 26.70 & 29.40 \\
\hline & $(10.35)$ & (9.863) & $(10.65)$ \\
\hline \multirow{2}{*}{ Nitrogen Dioxide $\left(\mu \mathrm{g} / \mathrm{m}^{3}\right)$} & 50.00 & 46.11 & 53.90 \\
\hline & $(21.06)$ & $(18.15)$ & $(22.96)$ \\
\hline \multirow[t]{2}{*}{ Sulfur Dioxide $\left(\mu \mathrm{g} / \mathrm{m}^{3}\right)$} & 4.710 & 4.667 & 4.752 \\
\hline & $(3.492)$ & $(3.600)$ & $(3.380)$ \\
\hline \multirow[t]{2}{*}{ Ozone $\left(\mu \mathrm{g} / \mathrm{m}^{3}\right)$} & 33.17 & 33.94 & 32.39 \\
\hline & $(17.86)$ & $(17.81)$ & $(17.86)$ \\
\hline \multirow[t]{2}{*}{ Temperature (Celsius) } & 11.76 & 11.86 & 11.67 \\
\hline & $(5.805)$ & $(5.763)$ & $(5.844)$ \\
\hline \multirow[t]{2}{*}{ Relative Humidity (\%) } & 76.63 & 75.51 & 77.75 \\
\hline & $(11.42)$ & $(11.46)$ & $(11.28)$ \\
\hline \multirow[t]{2}{*}{ Wind Speed (knot) } & 7.588 & 7.435 & 7.741 \\
\hline & $(4.036)$ & $(3.712)$ & $(4.330)$ \\
\hline \multirow[t]{2}{*}{ Rainfall (mm) } & 1.581 & 1.497 & 1.670 \\
\hline & $(3.526)$ & $(3.261)$ & $(3.786)$ \\
\hline \multirow[t]{2}{*}{ Unemployment } & 0.0506 & 0.0497 & 0.0514 \\
\hline & $(0.0155)$ & $(0.0152)$ & $(0.0158)$ \\
\hline \multirow[t]{2}{*}{ Atmospheric temp. difference (Celsius) } & 5.771 & & \\
\hline & (2.183) & & \\
\hline
\end{tabular}


Tube activity (million \# per week)

Police deployment $(\log )$ $\begin{array}{lc}1.677 & 1.721 \\ (2.248) & (2.304)\end{array}$

0.527

(0.379)

0.469

(0.293)

227760

455520
1.632

(2.190)

0.585

(0.441)

Observations

Notes: Standard deviations are in parentheses. Each observation corresponds to one of 730 days and one of 624 wards. Data as described in the text from the following sources: Air pollution data from DEFRA (2017), weather conditions from the Met Office (2012), house prices from HM Land Registry (2017), and crime data from Draca et al. (2011).

Table 2

Pooled and Fixed Effect Models of Air Pollution's Impact on Crime

\begin{tabular}{|c|c|c|c|c|c|c|}
\hline & \multicolumn{2}{|c|}{ Pooled PPML } & \multicolumn{4}{|c|}{ Fixed Effects PPML / OLS } \\
\hline & $(1)$ & (2) & (3) & $(4)$ & $(5)$ & $(6)$ \\
\hline \multirow[t]{2}{*}{ AQI (10units) } & $0.105^{* * *}$ & $0.036^{*}$ & $0.024^{* * *}$ & $0.012^{* * *}$ & $0.012^{* * *}$ & $0.457^{* * *}$ \\
\hline & $(0.0308)$ & $(0.0191)$ & $(0.0038)$ & $(0.0028)$ & $(0.0032)$ & $(0.1134)$ \\
\hline Controls & $\mathrm{N}$ & Y & Y & $\mathrm{Y}$ & Y & Y \\
\hline Ward FE & $\mathrm{N}$ & $\mathrm{N}$ & Y & $\mathrm{Y}$ & Y & Y \\
\hline DOW FE & $\mathrm{N}$ & $\mathrm{N}$ & $\mathrm{N}$ & $\mathrm{Y}$ & Y & Y \\
\hline Year-Month FE & $\mathrm{N}$ & $\mathrm{N}$ & $\mathrm{N}$ & $\mathrm{N}$ & Y & Y \\
\hline (Pseudo) $\mathrm{R}^{2}$ & 0.024 & 0.075 & 0.259 & 0.265 & 0.266 & 0.688 \\
\hline Observations & 455,520 & 433,277 & 433,277 & 433,277 & 433,277 & 433,277 \\
\hline
\end{tabular}

Notes: Each column in the table represents a separate regression. In column (1)-(5), the dependent variable is the number of criminal offences per day and Ward. The model is estimated using a Poisson pseudo maximum likelihood (PPML) specification with ward population as the offset. In column (6) the dependent variable is the crime rate per 100,000 people, and the model is estimated using a linear OLS specification. AQI is based on air pollution readings from the three closest AURN monitoring stations (weighted by inverse squared distance). Control variables include weather characteristics (temperature, relative humidity and wind speed), ward-level police deployment, tube activity and unemployment levels. Standard errors are cluster-robust in two dimensions, over Wards and 24 Year-Months. ${ }^{*} \mathrm{p}<0.1,{ }^{* *} \mathrm{p}<0.05,{ }^{* * *} \mathrm{p}<0.01$. 


\section{Table 3}

Air Pollution's Impact on Crime - Non-linear Models

\begin{tabular}{|c|c|c|c|c|}
\hline & \multicolumn{2}{|c|}{ Without Fixed Effects } & \multicolumn{2}{|c|}{ With Fixed Effects } \\
\hline & $\begin{array}{c}\text { No Controls } \\
\text { (1) }\end{array}$ & $\begin{array}{c}\text { Controls } \\
\text { (2) }\end{array}$ & $\begin{array}{c}\text { No Controls } \\
\text { (3) }\end{array}$ & $\begin{array}{c}\text { Controls } \\
\text { (4) }\end{array}$ \\
\hline Dummy for AQI & $0.087^{* * *}$ & $0.041^{* * *}$ & $0.046^{* * *}$ & $0.017^{* * *}$ \\
\hline$>20 \&<=25$ & $(0.0154)$ & $(0.0136)$ & $(0.0118)$ & $(0.0065)$ \\
\hline Dummy for AQI & $0.134^{* * *}$ & $0.053^{* * *}$ & $0.069^{* * *}$ & $0.024^{* * *}$ \\
\hline$>25 \&<=30$ & $(0.0223)$ & $(0.0199)$ & $(0.0149)$ & $(0.0071)$ \\
\hline Dummy for AQI & $0.191^{* * *}$ & $0.078^{* * *}$ & $0.085^{* * *}$ & $0.029^{* * *}$ \\
\hline$>30 \&<=35$ & $(0.0325)$ & $(0.0243)$ & $(0.0182)$ & $(0.0089)$ \\
\hline Dummy for $A Q I$ & $0.275^{* * *}$ & $0.105^{* * *}$ & $0.102^{* * *}$ & $0.037^{* * *}$ \\
\hline$>35$ & $(0.0660)$ & $(0.0355)$ & $(0.0204)$ & $(0.0091)$ \\
\hline Observations & 455,520 & 433,277 & 455,520 & 433,277 \\
\hline
\end{tabular}

Notes: See Table 2. Each column in the table represents a separate regression, all using PPML specifications. ${ }^{*} \mathrm{p}<0.1,{ }^{* *} \mathrm{p}<0.05,{ }^{* * *} \mathrm{p}<0.01$. 
Table 4

Air Pollution's Impact on Crime - Instrumental Variable Models using Wind Direction

\begin{tabular}{|c|c|c|c|c|c|c|}
\hline & \multicolumn{2}{|c|}{$\begin{array}{c}\text { Without } \\
\text { Instruments }\end{array}$} & \multicolumn{4}{|c|}{$\begin{array}{c}\text { With } \\
\text { Instruments }\end{array}$} \\
\hline & (1) & (2) & (3) & (4) & $(5)$ & (6) \\
\hline $\begin{array}{l}\text { AQI } \\
\text { (instrumented) }\end{array}$ & $\begin{array}{l}0.012^{* * *} \\
(0.0032)\end{array}$ & $\begin{array}{l}0.012^{* * *} \\
(0.0032)\end{array}$ & $\begin{array}{c}0.087^{* *} \\
(0.0398)\end{array}$ & $\begin{array}{l}0.024^{* * *} \\
(0.0075)\end{array}$ & $\begin{array}{l}0.026^{* * *} \\
(0.0079)\end{array}$ & $\begin{array}{l}0.945^{* * *} \\
(0.2652)\end{array}$ \\
\hline Controls & Y & Y & Y & $\mathrm{Y}$ & $\mathrm{Y}$ & Y \\
\hline Ward FE & Y & Y & $\mathrm{N}$ & Y & Y & $\mathrm{Y}$ \\
\hline DOW FE & Y & Y & $\mathrm{N}$ & $\mathrm{Y}$ & Y & Y \\
\hline Year-Month FE & Y & Y & $\mathrm{N}$ & $\mathrm{N}$ & Y & Y \\
\hline $\begin{array}{l}\text { First stage (F- } \\
\text { test) }\end{array}$ & & & 19.67 & 13.52 & 14.37 & 14.37 \\
\hline Observations & 433,277 & 431,026 & 431,026 & 431,026 & 431,026 & 431,026 \\
\hline
\end{tabular}

Notes: See Table 2 for description of full specification. Column (1) is identical to Table 2, Column 5. Column (2) is the same, but for the subset of observations for which the wind instrument exists. Columns (3)-(6) are instrumental variable estimates, equivalent to Columns (2),(4)-(6) of Table $2 .{ }^{*} \mathrm{p}<0.1,{ }^{* *} \mathrm{p}<0.05,{ }^{* * *} \mathrm{p}<0.01$. 
Table 5

Air Pollution's Impact on Crime - Different Levels of Aggregation

\begin{tabular}{|c|c|c|c|c|}
\hline & $\begin{array}{c}\text { No } \\
\text { Instrument } \\
(1) \\
\end{array}$ & $\begin{array}{c}\text { Instrument } \\
\text { (Wind) } \\
(2)\end{array}$ & $\begin{array}{c}\text { Instrument } \\
\text { (Inversion) } \\
(3)\end{array}$ & $\begin{array}{c}\text { Instrument } \\
\text { (Both) } \\
(4)\end{array}$ \\
\hline \multicolumn{5}{|c|}{ Panel A: Borough level } \\
\hline $\begin{array}{l}\text { AQI } \\
\text { (instrumented) }\end{array}$ & $\begin{array}{l}0.013^{* * *} \\
(0.0036)\end{array}$ & $\begin{array}{l}0.024^{* * *} \\
(0.0083)\end{array}$ & $\begin{array}{c}0.036^{*} \\
(0.0213)\end{array}$ & $\begin{array}{l}0.028^{* * *} \\
(0.0087)\end{array}$ \\
\hline Controls & $\mathrm{Y}$ & $\mathrm{Y}$ & $\mathrm{Y}$ & $\mathrm{Y}$ \\
\hline Borough FE & $\mathrm{Y}$ & $\mathrm{Y}$ & $\mathrm{Y}$ & $\mathrm{Y}$ \\
\hline DOW FE & $\mathrm{Y}$ & $\mathrm{Y}$ & $\mathrm{Y}$ & $\mathrm{Y}$ \\
\hline Year-Month FE & $\mathrm{Y}$ & $\mathrm{Y}$ & $\mathrm{Y}$ & $\mathrm{Y}$ \\
\hline First stage (F-test) & & 25.42 & 24.34 & 31.45 \\
\hline Observations & 21,767 & 21,765 & 21,767 & 21,765 \\
\hline \multicolumn{5}{|c|}{ Panel B: London level } \\
\hline $\begin{array}{l}\text { AQI } \\
\text { (instrumented) }\end{array}$ & $\begin{array}{l}0.014^{* * *} \\
(0.0044)\end{array}$ & $\begin{array}{l}0.023^{* * *} \\
(0.0083)\end{array}$ & $\begin{array}{c}0.033^{*} \\
(0.0197)\end{array}$ & $\begin{array}{l}0.026^{* * *} \\
(0.0077)\end{array}$ \\
\hline Controls & $\mathrm{Y}$ & $\mathrm{Y}$ & Y & $\mathrm{Y}$ \\
\hline DOW FE & $\mathrm{Y}$ & $\mathrm{Y}$ & $\mathrm{Y}$ & $\mathrm{Y}$ \\
\hline Year-Month FE & $\mathrm{Y}$ & $\mathrm{Y}$ & $\mathrm{Y}$ & $\mathrm{Y}$ \\
\hline First stage (F-test) & & 25.76 & 23.64 & 23.47 \\
\hline Observations & 701 & 701 & 701 & 701 \\
\hline \multicolumn{5}{|c|}{$\begin{array}{l}\text { Notes: Coefficient estimates for full model with all covariates (except ward-specific ones), all in } \\
\text { PPML specification. Panel A uses a sample with daily observations at the borough level; Panel B } \\
\text { uses a sample with daily observations collapsed into a single observation for all of London. 'Wind' } \\
\text { instrument is again the share of hours with wind blowing in either of } 4 \text { wind directions. 'Inversion' } \\
\text { instrument is the continuous temperature difference ground-level temperature readings from MIDAS } \\
\text { weather stations (London average) and NASA AIRS satellite readings of atmospheric temperature } \\
\text { at } 925 \mathrm{hPa} \text { pressure (ca. } 750 \mathrm{~m} \text { altitude). Standard errors are cluster-robust over } 24 \text { Year-Months. } \\
\mathrm{p}<0.1,{ }^{* *} \mathrm{p}<0.05,{ }^{* * *} \mathrm{p}<0.01 \text {. }\end{array}$} \\
\hline
\end{tabular}


Figure 1

Geographic coverage - London wards, AURN/MIDAS stations

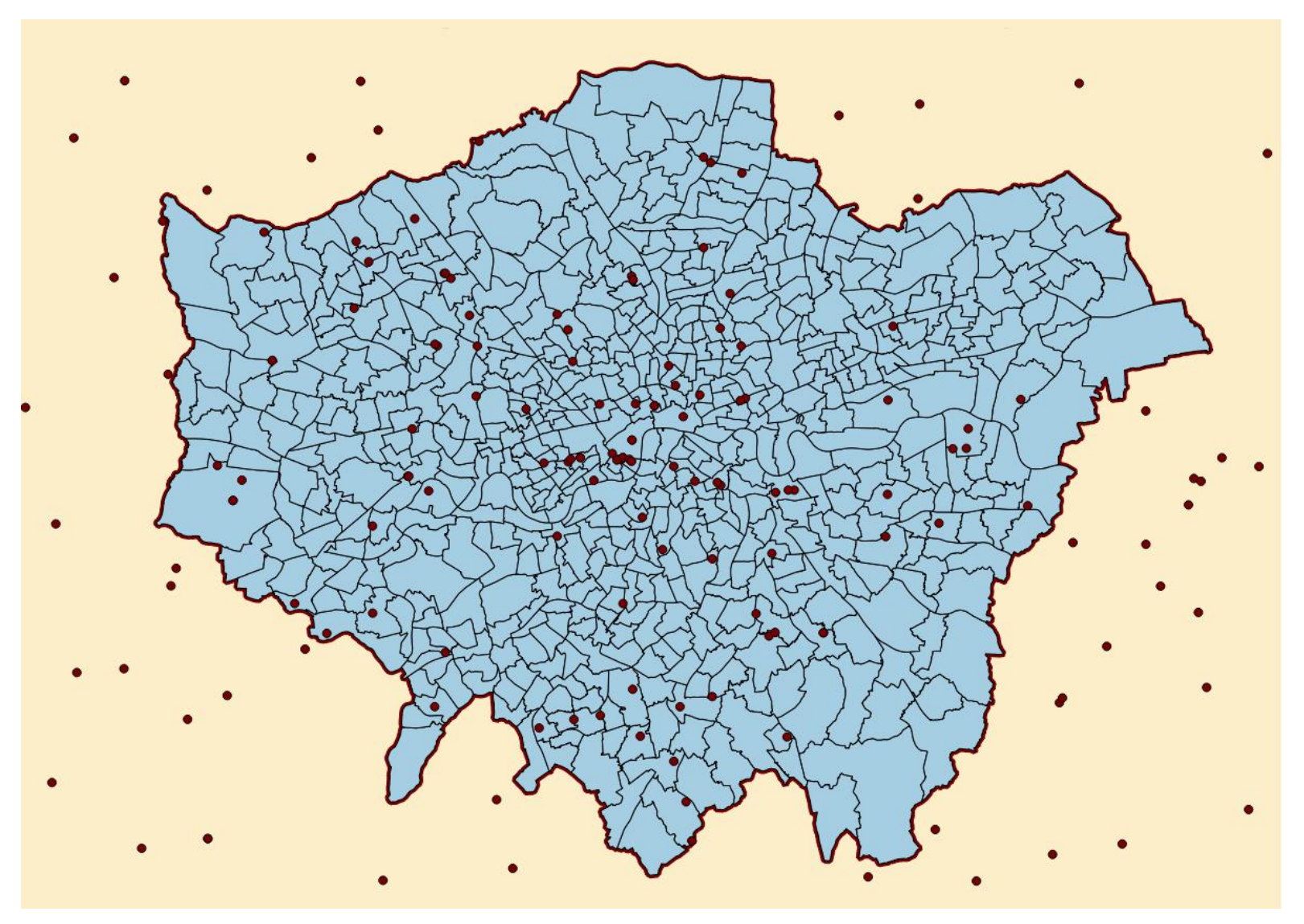

Notes: Geographic coverage of greater London, divided into 624 wards (excluding the City of London) and 96 AURN/MIDAS monitoring stations. 
Figure 2

AQI and Crime - Density plots
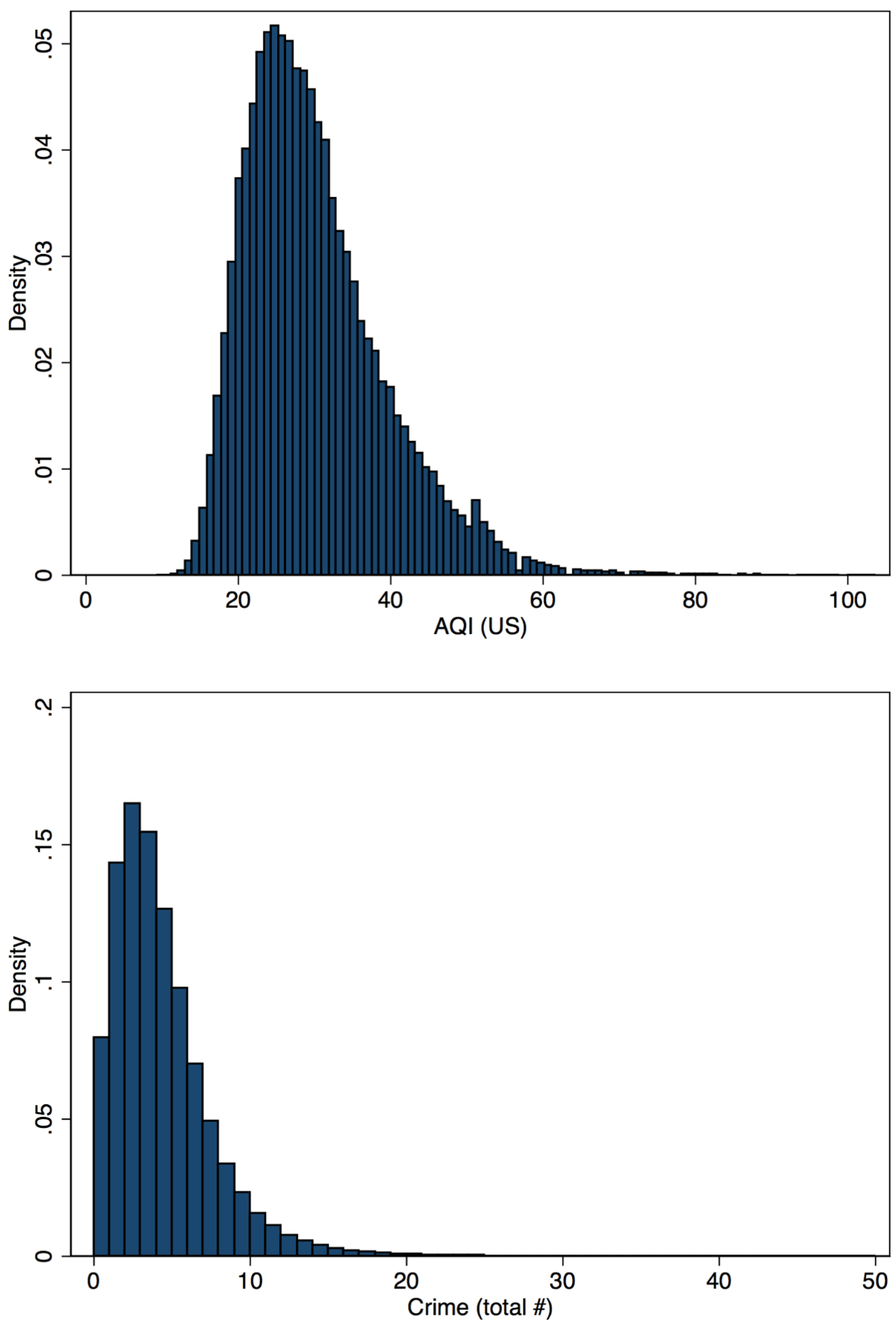

Notes: Density plots of air quality index (AQI) measurements and total number of criminal offences by day and ward. Data as described in the text. 
Figure 3

Residual AQI and Crime - Binned scatterplot

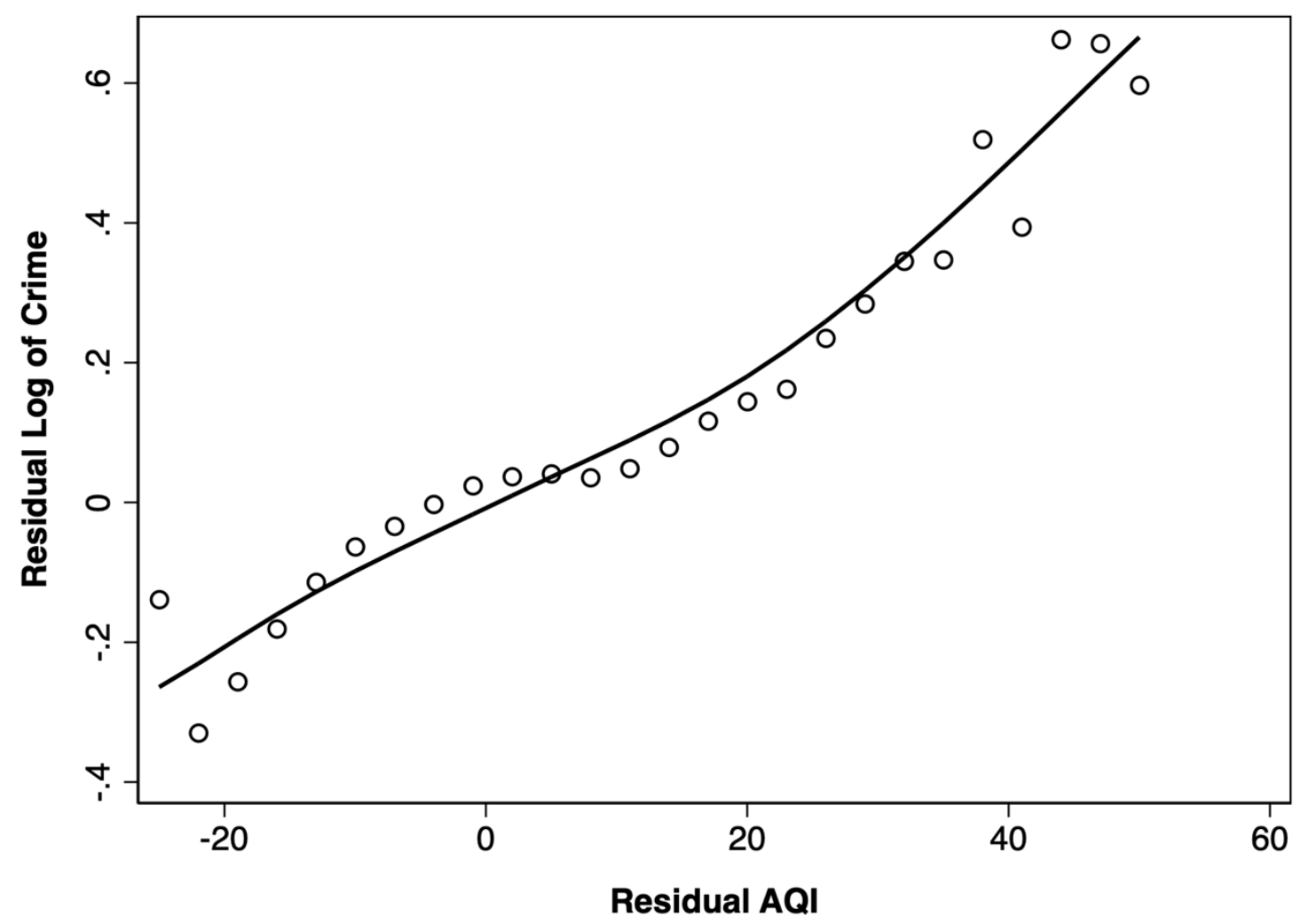

Notes: Plot of residual air quality index (AQI) and residual (log of) crime count. Residuals from a regression on ward fixed effects and weather controls. Data as described in the text. 
Figure 4

House prices - London wards

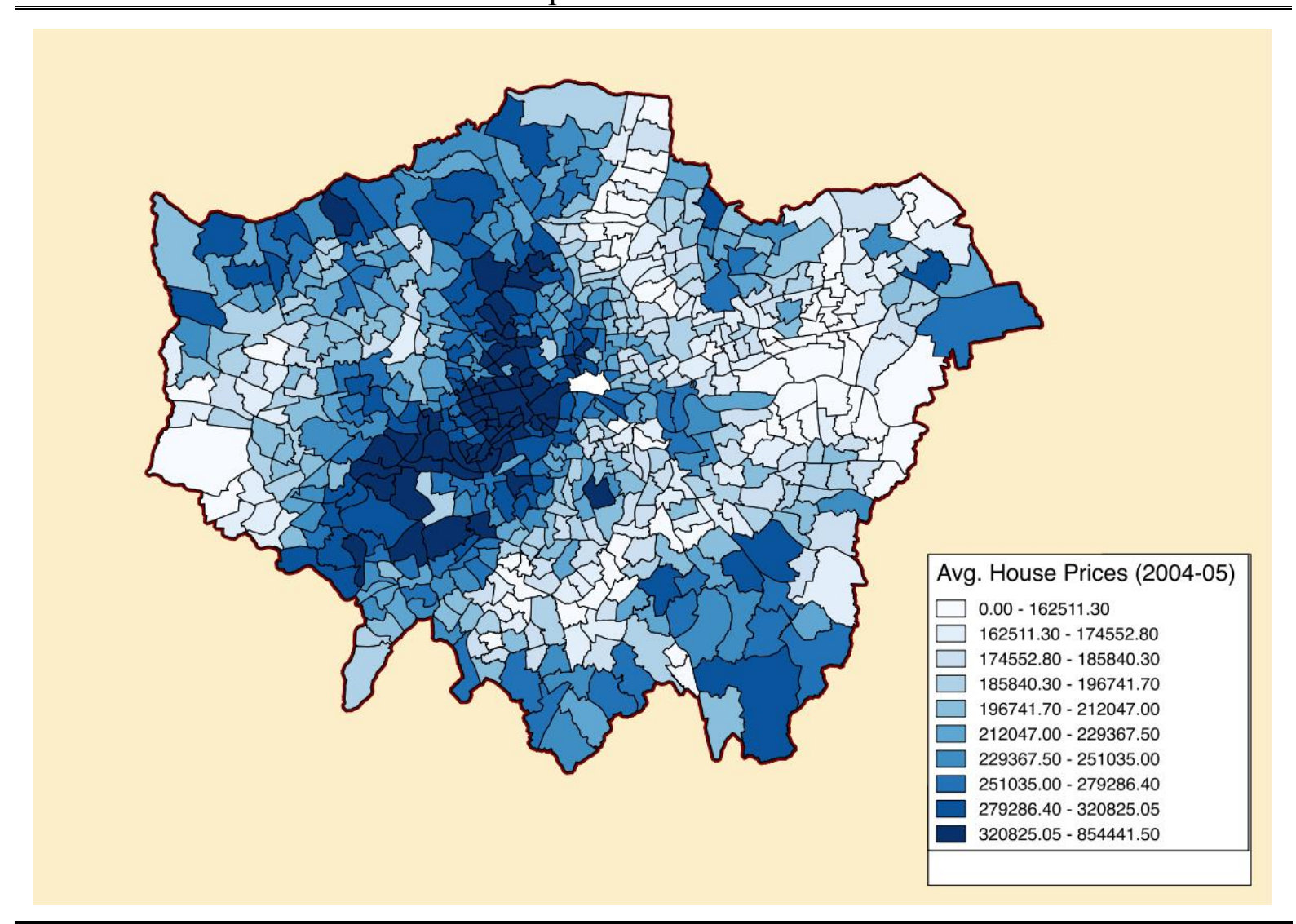

Notes: Average house prices over the 2004-2005 period by ward. Data as described in the text. 
Figure 5

The Effect of Air Pollution by House Price Quantile

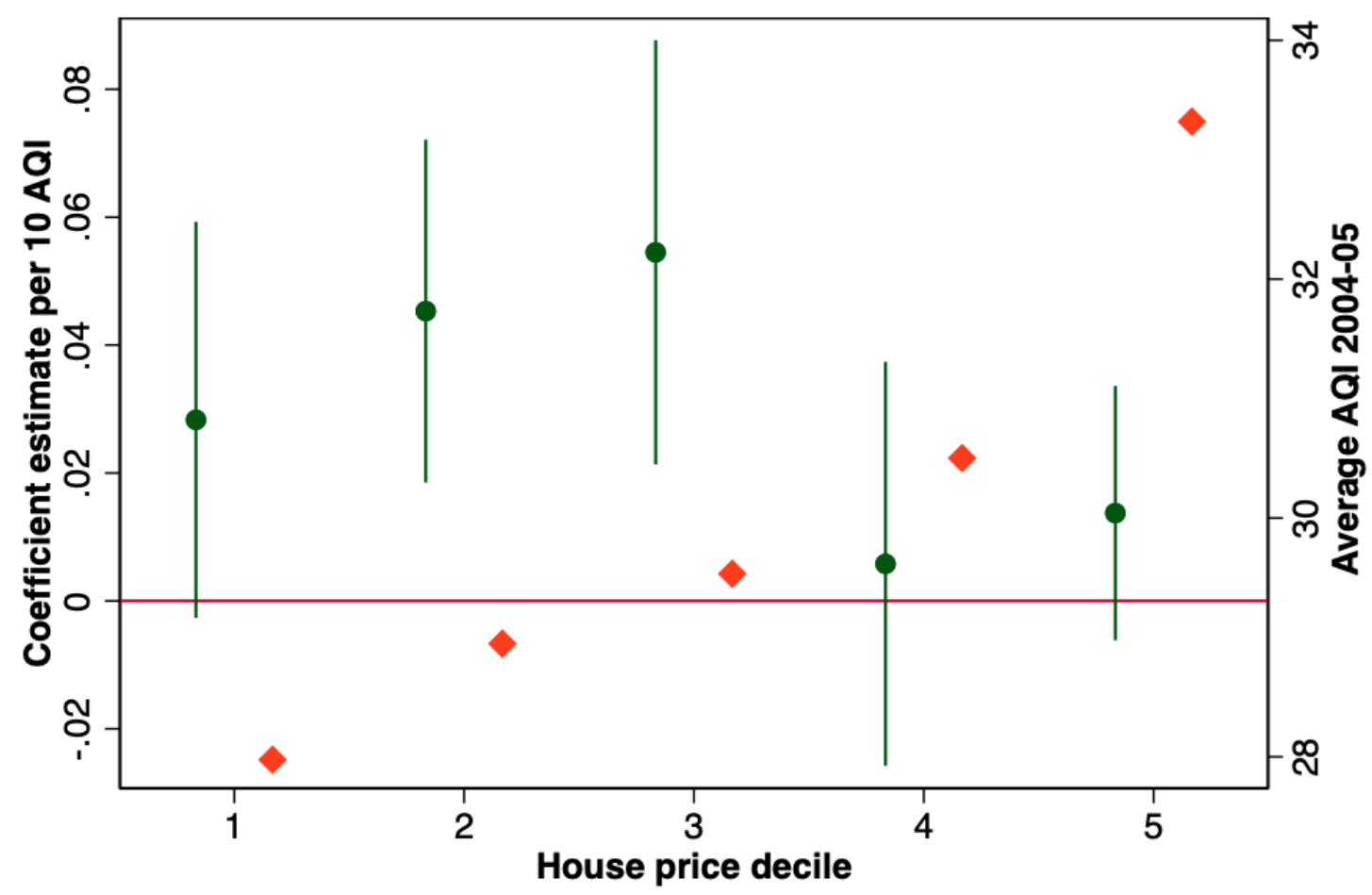

- Coefficient estimate (by quantile) $\diamond$ Mean AQI (by quantile)

Notes: Coefficient estimates and 95\% confidence intervals (left axis) of full instrumented model (same as Table 2, Column 5), estimated separately on sample stratified by 2004-2005 house price quantiles. Results are very similar for a single regression with interaction-terms for quantiles. Average AQI index by house price decile (right axis). Data as described in the text. 
Figure 6

The Effect of Air Pollution by Major Crime Type

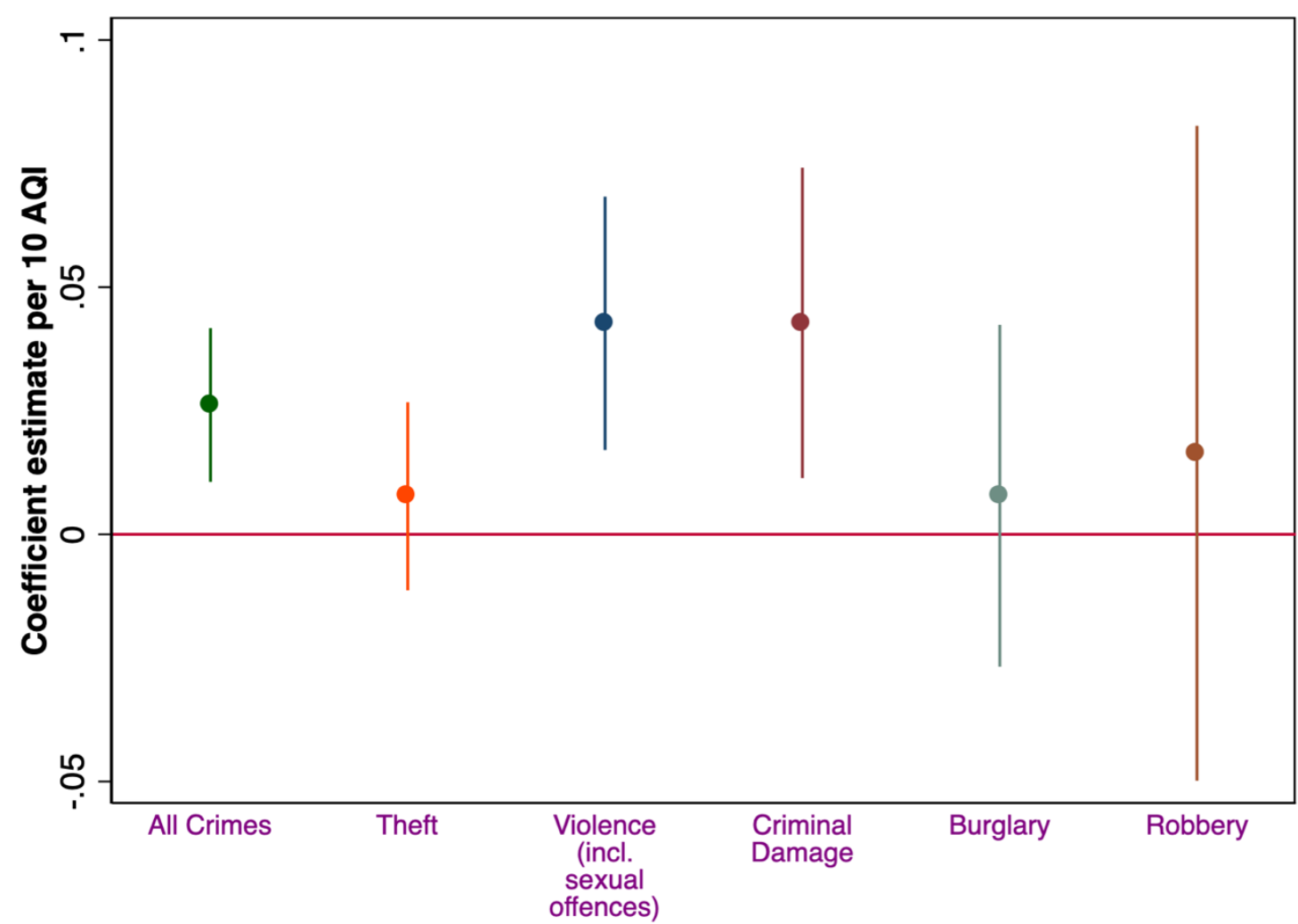

Notes: Coefficient estimates for separate estimations with different crime counts (5 largest major crime types) as outcome variable. Estimates from a full instrumented PPML specification with all covariates and fixed effects. Lines represent $95 \%$ confidence intervals. Data as described in the text. 
Figure 7

The Effect of Air Pollution by Crime Sub-Type

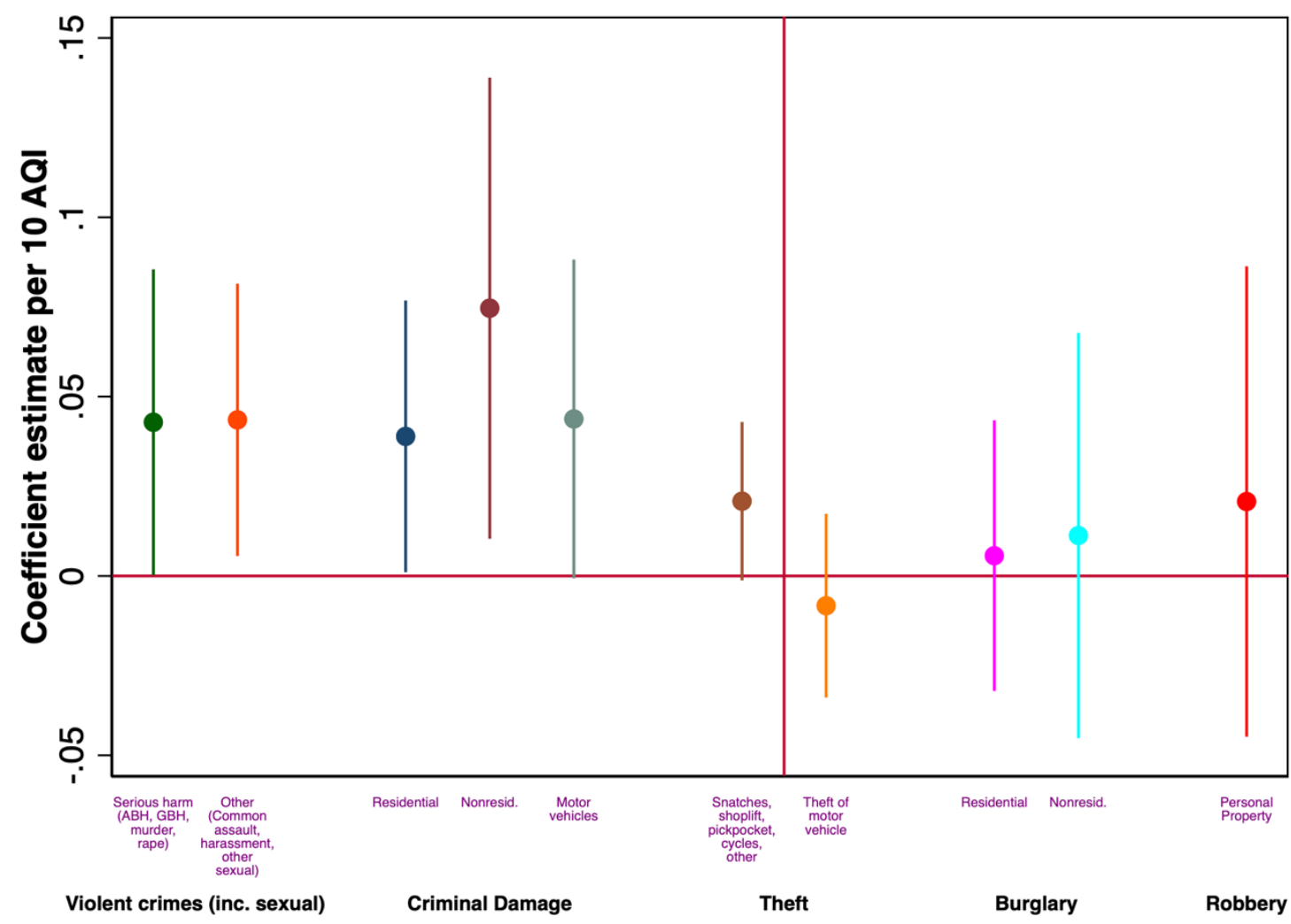

Notes: Coefficient estimates for separate estimations with different crime counts (crime sub-types) as outcome variable. Estimates from a full instrumented PPML model with all covariates and fixed effects. Lines represent $95 \%$ confidence intervals. Data as described in the text. 